\title{
Role of Tomato Extract in Protection against Damage Caused by Mesenteric Ischemia/ Reperfusion Induced in $\gamma$-Irradiated Rats
}

\author{
M. A. El-Ghazaly, E. S. El-Denshary*, H. A. Salem*, \\ Sh. M. Saad ${ }^{* *}$ and T. A. El-Hamoly** \\ Drug Radiation Research Dept., National Centre for Radiation \\ Research and Technology (NCRRT), "Dept. of Pharmacology \\ and Toxicology, Faculty of Pharmacy, Cairo University, Egypt \\ and ${ }^{* * *}$ Cyclotron Project, Nuclear Research Centre, Egypt.
}

\begin{abstract}
THE OBJECTIVE is, the protective effects of turmeric (Tur) as well as tomato extract (TE) against whole $\gamma$-irradiation injury of rats subjected to mesenteric ischemia/reperfusion (I/R). Male Wistar rats were divided into shame and irradiated groups.

Normal group subjected to sham-operation. Vitamin E (VE) treated-group served as a positive control. Ileal tissue samples were obtained to investigate glutathione (GSH), thiobarbituric reactive substances (TBARS), nitrite contents as well as activity of lactate dehydrogenase (LDH). In addition, cytokines; tumour necrosis factor-alpha (TNF- $\alpha$ ) and interleukin-6 (IL-6) were measured.

Intestinal I/R injury revealed a marked depletion in GSH, elevated TBARS and nitrite contents as well as low LDH activity. Moreover, there were remarkable increases in measured cytokines (TNF- $\alpha \& I L-6)$. The ischemic insults were exacerbated by acute $\gamma$-irradiation in most of measured parameters except for GSH and LDH activity. In I/R treated-groups, TE could restore GSH contents and LDH (cell membrane integrity) as compared with VE with no lipid peroxidation protection. However, both supplements corrected levels of nitrite and TNF- $\alpha$. Either Tur or TE could correct most of biochemical changes in irradiated rats. In general, both supplements recorded antioxidant and antiinflammatory effects upon irradiation.

Keywords: Intestine, oxidative stress, radiotherapy, ischemia, cytokines, turmeric, tomato.
\end{abstract}

The practice use of radiotherapy was found to participate in different cardiovascular disorders. Previously, it has been suggested that radiation therapy could be a direct cause of many arterial diseases (Benoff and Schweitzer, 1995). Some studies have described post-irradiation changes of 
smooth muscle cells and/ or endothelium of vessels; leading to destruction and hence ischemic effects (Hopewell et al., 1986). Generation of free radicals during $\gamma$-irradiation is considered as the most important indirect mechanism of radiation injury (Dubner et al., 1995). Reperfusion of the gut after an ischemic episode is accompanied with a progressive injury of mucosal structure and eventually leads to a complete loss of barrier integrity and consequently bacterial translocation (Stalliona et al., 2005). Such case manifests an enhancement in production of reactive oxygen species (ROS), lipid mediators and a modification in nitric oxide levels (Eppihimer and Granger, 1997). Considerably, it has been accepted that the two methods of damage, I/R and $\gamma$-radiation up-regulate the expression of different inflammatory cytokines in intestine by activation of transcriptional factors such as nuclear factor-кB (Ichikawa et al., 1997 and Linard et al., 2003). Under most circumstances, the concept of pharmacologic therapy for intestinal ischemia is still tentative. Therefore, there is a great attention to function dietary supplements in balancing oxidation or even inducing cellular antioxidants. VE is available in different pharmaceutical products as a supplement and antioxidant. By regulating mitochondrial generation of superoxide and related ROS, it is not only attenuates oxidative damage but also modulates the expression and activation of related signal transduction pathways (Chow, 2003). Naturally, tomato products contain their strategic constituent lycopene in combination with other related phytochemicals, including phytoene and phytofluene (Ronen et al., 1999). Lycopene as one of the most potent antioxidants; has been suggested to prevent carcinogenesis and atherogenesis by protecting critical bio molecules including proteins, lipids, low density lipoprotein and DNA (Agarwal and Rao, 1998 and Pool-Zobel et al., 1997). Owing to its high number of conjugated double bonds, it exhibits high scavenging ability towards ROS (Yaping et al., 2002).

This study was carried out to outline the potential use of antioxidants as adjuvant therapy; in order to overcome the morbidity resulted from ischemic risk factor which appears frequently with utilization of radiotherapy for malignant patients.

\section{Material and Methods}

\section{Animals}

Adult male Wistar rats (150-250 g) were kept under standard environments. The Study was carried out according to the guidelines of the ethical committee in Faculty of Pharmacy, Cairo University.

Egypt. J. Rad. Sci. Applic., Vol. 24, No. 2 (2011) 
Drugs

VE (dl- $\alpha$-tocopheryl acetate), Sigma-Alderch, USA. Tomato powder extract (containing 6\% lycopene), the Arab Company for Gelatin and Pharmaceutical Products, Alexandria, Egypt.

\section{Methods}

\section{Irradiation of animals}

Irradiation was carried out at the NCRRT, Egypt. Rats were subjected to whole body (6 Gy) $\gamma$-rays using the Gamma Cell-40 biological irradiator $\left({ }^{137}\right.$ Caesium-source) at a dose rate of $0.72 \mathrm{~Gy} / \mathrm{min}$.

\section{Ileal ischemia/ reperfusion}

Rats were anaesthetized and ischemia was induced by total occlusion of the superior mesenteric artery using a mini-clamp. After $30 \mathrm{~min}$ ischemia, reperfusion was initiated by removal of the clamp and maintained for another 30 min (Souza et al., 2000).

\section{Experimental design}

Animals were randomly divided into 9 experimental groups each of eight rats. All groups, except the sham-operated were subjected to ileal I/R and four of them were exposed to $\gamma$-rays at a dose level of $6 \mathrm{~Gy}$. The first group, which served as control, underwent laparatomy without I/R injury. The following two groups were served as untreated groups (I/R \& irradiated I/R). The fourth group pre-treated with $(100 \mathrm{mg} / \mathrm{kg}$ / day, per tubes), VE diluted with corn oil (Yilmaz and Yilmaz, 2006) (VE+ I/R group). The fifth group administered $(67 \mathrm{mg} / \mathrm{kg} /$ day, per tubes), TE dissolved in corn oil (Liu et al., 2003) (TE+ I/R group). The sixth group received an equivalent volume of corn oil vehicle served as control of the VE and TE-treated group (Vehicle+ I/R group). The groups (7, $8 \& 9$ ) were irradiated one $h$ before induction of $\mathrm{I} / \mathrm{R}$ protocol. They received the same treatment regimens as the three former groups (VE+ irradiated I/R, TE+ irradiated $\mathrm{I} / \mathrm{R}$ and Vehicle+ irradiated $\mathrm{I} / \mathrm{R}$ ). All the treatments were received once daily for 14 consecutive days. Twenty-four $h$ after the last dose administration, the rats were anaesthetized with urethane $(1.2 \mathrm{mg} / \mathrm{kg}$, inter peritoneum (i.p.) and subjected to laparotomy.

\section{Biochemical analysis}

After $30 \mathrm{~min}$ of reperfusion, tissue sample from the mid portion of the ileum was excised. The tissues homogenates were used for estimation of GSH 
content as described previously by (Beutler et al., 1963), TBARS content according to the method of (Uchiyama and Mihara, 1978), cytosolic LDH activity (Buhl and Jackson, 1978) as well as the contents of nitrite (Green et al., 1982) and pro-inflammatory cytokines (TNF- $\alpha$ \& IL-6) by commercial kits.

\section{Statistical analysis}

All values were presented as means \pm S.E.M. One-way analysis of variance (ANOVA) followed by Tukey Kramer multiple comparison test was used to determine the difference between the groups in terms of all studied parameters using Graphpad Instat software (version 2). Results were considered statistically significant when $p<0.05$.

\section{Results}

\section{Effect of VE and tomato extract on ileal oxidative stress}

Pre-treatment with VE did not buffer GSH depletion as compared to I/R group. In comparison, I/R-induced ileal GSH content reduction was markedly ameliorated by TE pre-administration ( $68.3 \%$ protection), Table 1 .

TABLE 1. Evaluation of oxidative stress in non irradiated rats.

\begin{tabular}{|c|c|c|c|c|}
\hline $\begin{array}{c}\text { Non-irradiated } \\
\text { I/R }\end{array}$ & Sham-operated & Vehicle & Vitamin E & Tomato extract \\
\hline $\begin{array}{c}\text { GSH } \\
(\mathrm{mg} / \mathrm{g} \text { wet tissue) }\end{array}$ & $27.9 \pm 1.2$ & $17.6 \pm 1.1^{\mathrm{a}}$ & $20.3 \pm 1.9^{\mathrm{a}}$ & $24.8 \pm 2.2^{\mathrm{b}}$ \\
\hline $\begin{array}{c}\text { TBARS } \\
(\mathrm{nmol} / \mathrm{g} \text { wet tissue })\end{array}$ & $84.6 \pm 1.7$ & $106.4 \pm 5.2^{\mathrm{a}}$ & $88.6 \pm 5.2^{\mathrm{b}}$ & $107.30 \pm 38^{\mathrm{ac}}$ \\
\hline $\begin{array}{c}\text { Nitrite } \\
(\mu \mathrm{mol} / \mathrm{g} \text { wet tissue) }\end{array}$ & $0.24 \pm 0.03$ & $0.81 \pm 0.02^{\mathrm{a}}$ & $0.35 \pm 0.04^{\mathrm{b}}$ & $0.3 \pm 0.07^{\mathrm{b}}$ \\
\hline \multicolumn{4}{|c|}{$\begin{array}{c}{ }^{\mathrm{a}} \text { Significantly different from the sham-operated group. } \\
\text { the vehicle received-groups. }\end{array}$}
\end{tabular}

Upon irradiation, both supplements showed a significant protection against such depletion amounting $79.8 \%$ and $113.3 \%$, Table 2 . On other hand, oral administration of VE showed a protection $(81.7 \%)$ against $\mathrm{I} / \mathrm{R}$-induced lipid peroxidation. This was parallel to its protective effect $(22 \%)$ against I/Rinduced cell membrane injury. In contrary, Pre-treatment with TE did not show marked correction in TBARS contents caused by I/R injury, Table 1 . Even though, it showed around 3.1-fold increase in I/R-induced cytosolic LDH activity decrease as for VE-treated group, Fig. 1A). In comparison with VE, TE-treated group revealed about 3 times less protection against lipid Egypt. J. Rad. Sci. Applic., Vol. 24, No. 2 (2011) 
peroxidation and around 2-fold decrease in protection against enhanced LDH activity of irradiated I/R group, Table 2 \& Fig. 1B).

TABLE 2. Evaluation of oxidative stress in 6Gy irradiated rats.

\begin{tabular}{|c|c|c|c|c|}
\hline $\begin{array}{c}\text { Irradiated } \\
\text { I/R }\end{array}$ & Sham-operated & Vehicle & Vitamin E & Tomato extract \\
\hline $\begin{array}{c}\text { GSH } \\
(\mathrm{mg} / \mathrm{g} \text { wet tissue })\end{array}$ & $27.9 \pm 1.2$ & $21.6 \pm 1.2^{\mathrm{a}}$ & $26.1 \pm 1.1^{\mathrm{d}}$ & $29.1 \pm 1.2^{\mathrm{d}}$ \\
\hline $\begin{array}{c}\text { TBARS } \\
(\mathrm{nmol} / \mathrm{g} \text { wet tissue })\end{array}$ & $84.6 \pm 1.7$ & $132.2 \pm 5.2^{\mathrm{a}}$ & $87.7 \pm 4.4^{\mathrm{d}}$ & $118.6 \pm 3.5^{\mathrm{ade}}$ \\
\hline $\begin{array}{c}\text { Nitrite } \\
(\mu \mathrm{mol} / \mathrm{g} \text { wet tissue })\end{array}$ & $0.24 \pm 0.03$ & $1.1 \pm 0.08^{\mathrm{a}}$ & $0.63 \pm 0.04^{\mathrm{ad}}$ & $0.60 \pm 0.06^{\mathrm{ad}}$ \\
\hline
\end{tabular}

Legends as in Table 1.

Pre-administration of either VE or TE showed a protection against I/Rinduced elevation in ileal nitrite content of non-irradiated rats recording $81 \%$ and $60 \%$, respectively. For irradiated pattern, TE afforded a protection against elevated content of nitrite (amounting $88.4 \%$ ). However, VE showed just a $56.8 \%$ protection against such elevation, Table 2 .
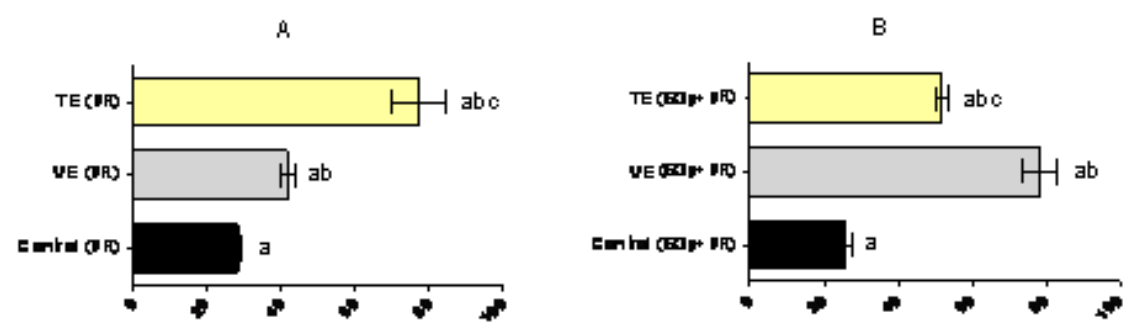

Fig. 1. Effect of VE $(100 \mathrm{mg} / \mathrm{kg})$ and tomato extract $(67 \mathrm{mg} / \mathrm{kg})$ administered orally for 14 successive days on cytosolic LDH activity (A) non-irradiated rats subjected to ileal $I / R(30 \mathrm{~min} / 30 \mathrm{~min})$ or $(B)$ irradiated rats (6 Gy) subjected afterward into $\mathbf{I} / \mathbf{R}$.

All expressed data are $\%$ of sham-operated group. Each column represents the mean of 8 experiments \pm SEM. ${ }^{\mathrm{a}} p<0.05$ compared to normal group, ${ }^{\mathrm{b}} \mathrm{p}<0.05$ compared to I/R group, ${ }^{\mathrm{c}} \mathrm{p}<0.05$ compared to VE group. Tomato Extract (TE), Vitamin E (VE).

\section{Effect of VE \& TE on pro-inflammatory cytokines levels of ileal tissues}

VE recorded $32.4 \%$ and $35 \%$ protections against the increase in ileal contents of TNF- $\alpha$ and IL- 6 , respectively. On comparison with VE-treated group, TE afforded 1.5 more protection against I/R-induced elevation of TNF- $\alpha$ without any effect against IL-6 increase (Fig. $2 \& 3$ A). Oral administration of either VE or TE could correct the increased TNF- $\alpha$ contents of irradiated 
animals amounting 19.3 and $41.6 \%$, respectively. However, both supplements did not provide any protection against the hazardous elevated ileal IL- 6 contents (Fig. $2 \& 3 \mathrm{~B}$ ).
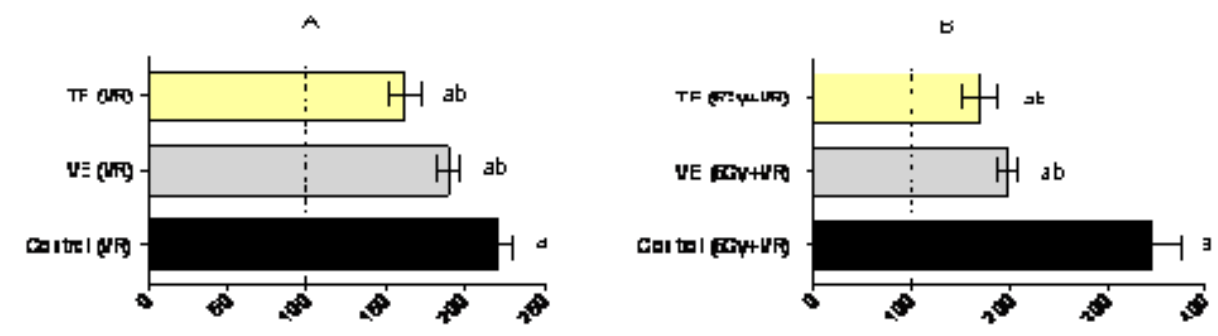

Fig. 2. Effect of VE $(100 \mathrm{mg} / \mathrm{kg})$ and tomato extract $(67 \mathrm{mg} / \mathrm{kg})$ administered orally for 14 successive days on ileal TNF- $\alpha$ contents (A) non-irradiated rats subjected to ileal $\mathbf{I} / \mathbf{R}(30 \mathrm{~min} / 30 \mathrm{~min})$ or $(B)$ irradiated rats $(6 \mathrm{~Gy})$ subjected afterward into $\mathbf{I} / \mathbf{R}$.

Legends as in Fig. 1.

A

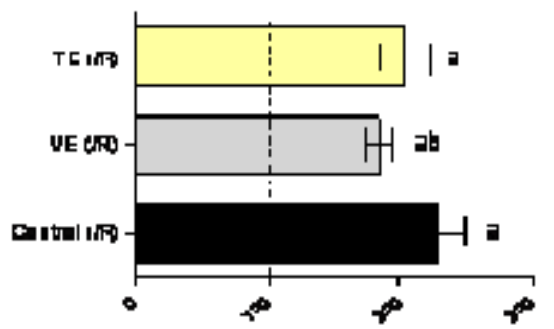

日

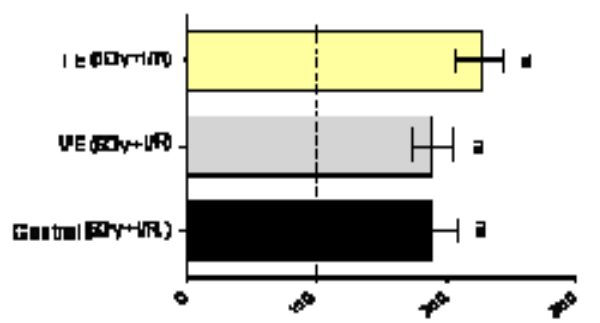

Fig. 3. Effect of $V E(100 \mathrm{mg} / \mathrm{kg})$ and tomato extract $(67 \mathrm{mg} / \mathrm{kg})$ administered orally for 14 successive days on ileal IL-6 contents (A) non-irradiated rats subjected to ileal $\mathbf{I} / \mathbf{R}(30 \mathrm{~min} / 30 \mathrm{~min})$ or $(B)$ irradiated rats (6 Gy) subjected afterward into $I / R$.

Legends as in Fig. 1.

\section{Discussion}

Under normal condition, the amount of ROS produced is under the control exerted by the antioxidant defence mechanisms. However, during oxidative stress such defence mechanisms may be overwhelmed and consequently damage may occur. The present results clearly demonstrated that $\mathrm{I} / \mathrm{R}$ significantly increased the oxidative damage of intestine which worsens by $\gamma$-irradiation. Previously, it was found that reduced form of GSH (water soluble) may act as a first line of defence against oxidative stress during $\mathrm{I} / \mathrm{R}$ while lipid soluble antioxidants may act later on during severe oxidative stress (Tracey et Egypt. J. Rad. Sci. Applic., Vol. 24, No. 2 (2011) 
al., 1999). There for VE (lipid soluble) showed no significant effect against ileal GSH content depletion of rats subjected to mild I/R (30 $\mathrm{min} / 30 \mathrm{~min})$. However, $\gamma$-radiation may contribute to exaggeration of the severity of oxidative stress caused by I/R. Pre-treatment with VE provided significant protection against lipid peroxidation induced by ileal $\mathrm{I} / \mathrm{R}$. This could be manifested by the observed decrease in ileal TBARS content and the increase in LDH activity as well. Also the present results showed a further protection against lipid peroxidation and restoration in cell membrane injury by VE in $\gamma$-irradiated animals. Such observations are in accordance with that reported by Yilmaz and Yilmaz (2006) on rat model. Furthermore, oral administration of VE protected against I/R-induced elevation of ileal nitrite content in either irradiated or nonirradiated animals. This effect of VE could be attributed to its antioxidant potential with a consequent protection against oxidative stress-induced iNOS activation (Guney et al., 2007). In addition, VE decreased the extent of elevations in ileal cytokines (TNF- $\alpha$ and IL-6). Similar pattern of protection has been previously reported following myocardial I/R (Xu et al., 2005). This could be explained on the basis that VE may inhibit the capacity of ROS to activate redox-sensitive signalling pathways that induce the expression of cytokine genes (Pathania et al., 1999).

Pre-treatment with TE showed a remarkable protection against I/R-induced ileal GSH depletion. Similar finding has been observed in myocardial I/R model (Bansal et al., 2006). This effect could be a result of the antioxidant activity of lycopene, TE component, to modulate different phase II enzymes like glutathione-S-transferase, reductase and peroxidase in different experimental models (Breinholt et al., 2000). Moreover, a further increase of the GSH content attributed to daily oral administration of TE was observed in irradiated rats. This was parallel with the observation of (Saada et al., 2010) on lycopene effect on small intestine of irradiated (6 Gy) rats. On other hand, no significant protection against elevation of ileal TBARS content was demonstrated with TE in I/R model. Such result might not exclude the protective effect of TE as partly manifested by the present protection against ischemic-induced decrease in LDH activity in either irradiated or non-irradiated rats. In irradiated group, lycopene reduced the rise of TBARS. Administration of TE showed a significant reduction of ileal nitrite content of either rats subjected to I/R alone or with $\gamma$ -

Egypt. J. Rad. Sci. Applic., Vol. 24, No. 2 (2011) 
radiation. Similar results were previously reported by Hsiao et al. (2004) on cerebral ischemic rats. Another effect of lycopene that could also contribute to such reduction in NO is the reduction in TNF- $\alpha$ production, as observed in the present study. Similar findings were previously observed by other investigators (Herzog et al., 2005 and Li et al., 2007). These results of TE may be attributed mainly to the antioxidant-sparing action of lycopene. It considered as the most

potent singlet oxygen quencher because of its high number of conjugated dienes (Yaping et al., 2002). During such process, energy is transferred from the singlet oxygen to the lycopene molecule, which is converted into energy rich triplet state that scavenges other ROS and RNS (Atessahin et al., 2006).

In conclusion, immediate $\gamma$-irradiation showed a disturbance in the measured biochemical parameters. The same dose administration of different dietary supplements revealed more protection against such hazards in irradiated models than non-irradiated ones. These findings give an attention toward further studies on cellular effects of immediate acute $\gamma$-radiation after herbal medicine administrations.

\section{References}

Agarwal, S. and Rao, A. V. (1998) Tomato lycopene and low density lipoprotein oxidation: a human dietary intervention study. Lipids, 33, 981.

Atessahin, A., Karahan, I., Turk, G., Gur, S., Yilmoz, S. and Ceribasi., A. (2006) Protective role of lycopene on cisplatin-induced changes in sperm characteristics, testicular damage and oxidative stress in rats. Reprod. Toxicol., 21, 42.

Bansal, P., Gupta, S., Ojha, S., Nandave, M., Mittal, R., Kumari, S. and Arya, D. (2006) Cardioprotective effect of lycopene in the experimental model of myocardial ischemia-reperfusion injury. Mol. Cell Biochem., 289, 1.

Benoff, L. J. amd Schweitzer, P. (1995) Radiation therapy-induced cardiac injury. Am. Heart J., 129, 1193.

Beutler, E., Duron, O. and Kelly, B. M. (1963) Improved method for the determination of blood glutathione. J. Lab. Clin. Med., 61, 882.

Breinholt, V., Lauridesn, S.T., Daneshvar, B., Jakabesen, J. (2000) Dose-response effect of lycopene on selected drug-metabolizing and antioxidant enzymes in the rat. Cancer Lett., 154, 201.

Buhl, S. N. and Jackson, K. Y. (1978) Optimal conditions and comparison of lactate dehydrogenase catalysis of the lactate-to-pyruvate-to-lactate reactions in human serum at 25,30 and $37^{\circ} \mathrm{C}$. Clin. Chem., 24, 828 .

Egypt. J. Rad. Sci. Applic., Vol. 24, No. 2 (2011) 
Chow, C. K. (2000) Vitamin E regulation of mitochondrial superoxide generation. Biol. Signals Recept., 10, 112.

Dubner, D., Gisone, P., Jaitovich, I. and Perez, M. (1995) Free radicals production and estimation of oxidative stress related to $\mathrm{g}$ irradiation. Biol. Trace Elem. Res., 47, 265.

Eppihimer, M. J. and Granger, D. N. (1997) Ischemia/reperfusion induced leukocyteendothelial interactions in postcapillary venules. Shock, 7, 1.

Guney, M., Ozguner, F., Oral, B., Karahan, N. and Mungan, T. (2007) $900 \mathrm{MHz}$ radiofrequency-induced histopathologic changes and oxidative stress in rat endometrium: protection by vitamins E and C. Toxicol. Ind. Health, 23, 4110.

Herzog, A., Siler, U., Spitzer, V., Seifert, N., Denelavas, A., Hunziker, P. B., Hunziker, W., Goralczyk, R. and Wertz, K. (2005) Lycopene reduced gene expression of steroid targets and inflammatory markers in normal rat prostate. FASEB J., 19, 272.

Hopewell, J. W., Campling, D., Calvo, W., Reinhold, H. S., Wilkinson, J. H., Yeng T. K. (1986) Vascular irradiation damage: its cellular basis and likely consequences. Br. J. Cancer, 53, 181.

Hsiao, G., Fong, T. H., Tzu, N. H., Lin, K. H., Chou, D. S., Sheu, J. R. (2004) A potent antioxidant, lycopene, affords neuroprotection against microglia activation and focal cerebral ischemia in rats. In vivo, 18, 351.

Ichikawa, H., Flores, S., Kvietys, P. R., Wolf, R. E., Yoshikawa, T., Granger, D. N. and Aw, T. (1997) Molecular mechanisms of anoxia-reoxygenation-induced neutrophil adherence to cultured endothelial cells. Circ. Res., 81, 922.

Li, B. H., Zhang, Q. X., Dong, D. J., Lin, X. M. (2007) Effect of lycopene on immunity in rats with acute lung injury. Beijing Da. Хие. Хие. Вао., 39, 77.

Liu, C., Lian, F., Smith, D. E., Russell, R. M. and Wang, X. D. (2003) Lycopene supplementation inhibits lung squamous metaplasia and induce apoptosis via up-regulating insulin-like growth factor-binding protein 3 in cigarette mokeexposed ferrets. Cancer Res., 63, 3138.

Green, L. C., Wagner, D. A., Glogowski, J., Skipper, P. L., Wishnok, G. S. and Tannenbaum, S. R. (1982) Analysis of nitrate, nitrite and [15N] nitrate in biological fluids. Anal. Biochem., 126, 131.

Pathania, V., Syal, N., Pathak, C. M. and Khanduja, K. L. (1999) Vitamin E suppresses the induction of reactive oxygen species release by lipopolysaccharide, IL-1 $\beta$ and TNF- $\alpha$ in rat alveolar macrophages. J. Nutr. Sci. Vitaminol., 45, 675.

Pool-Zobel, B., Bub, A., Muller, H. and Rechkemmer, G. (1997) Consumption of vegetables reduces genetic damage in humans: first result of a human intervention trial with carotenoid-rich foods. Carcinogenesis, 18, 1847. 
Ronen, G., Cohen, M., Zamir, D. and Hirschberg, J. (1999) Regulation of carotenoid biosynthesis during tomato fruit development: expression of the gene for lycopene epsilon-cyclase is down-regulated during ripening and is elevated in the mutant. Plant J., 17, 341.

Saada, H. N., Rezk, R. G. and Eltahawy, N. A. (2010) lycopene protects the structure of the small intestine against gamma-radiation-induced oxidative stress. Phytother. Res., 24, 204.

Souza, D., Cara, D., Cassali, G., Coutinho, S., Silveira, M., Andrade, S., Poole, S. and Teixeira, M. (2000) Effects of the PAF receptor antagonist UK74505 on local and remote reperfusion injuries following ischemia of the superior mesenteric artery in the rat. Br. J. Pharmacol., 131, 1800.

Stallion, A., Kou, T. D., Latifi, S. Q., Miller, K. A., Dahms, B. B., Dudgeon, D. L. and Levine, A. D. (2005) Ischemia/reperfusion: a clinically relevant model of intestinal injury yielding systemic inflammation. J. Ped. Surg., 40, 470.

Tracey, K. J., Fong, Y., Hesse, D. G., Manogue, K. R., Lee, A. T. and Tribble, D. L. (1999) AHA Science Advisory. Antioxidant consumption and risk of coronary heart disease: emphasis on vitamin C., vitamin E, and betacarotene: A statement for healthcare professionals from the American Heart Association. Circulation, 99, 591.

Uchiyama, M. and Mihara, M. (1978) Determination of malonaldehyde precursor in tissues by thiobarbituric acid test. Anal. Biochem., 86, 271.

Xu, Y., Gen, M., Lu, L., Fox, J., Weiss, S. O., Brown, R. D., Perlov, D., Ahmad, H., Zhu, P., Greyson C, Long, C. S. and Schwartz, G. G. (2005) PPARgamma activation fails to provide myocardial protection in ischemia and reperfusion in pigs. Am. J. Physiol., 288, H1314-.

Yaping, Z., Suping, Q., Weni, Y., Zheng, X., Hong, S., Side, Y. and Dapu, W. (2002) Antioxidant activity of lycopene extracted from paste towards trichloromethyl peroxyl radical. Food Chem., 77, 209.

Yilmaz, S. and Yilmaz, A. (2006) Effects of melatonin and vitamin E on oxidativeantioxidative status in rats exposed to irradiation. Toxicol., 222, 1.

(Received: 23/01/2012;

accepted: 26/02/2012)

Egypt. J. Rad. Sci. Applic., Vol. 24, No. 2 (2011) 
دور الكركم و مستخلص الطماطم في الوقايـة من التلف النـاتج

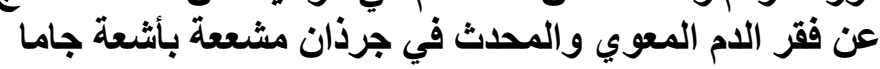
منى عبد اللطيف الغزالي و عز الدين الانشـاري* و هشـام علي سـالم* و شكري

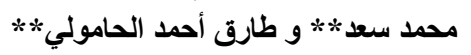

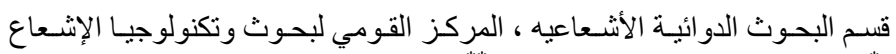

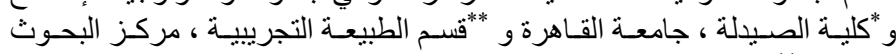

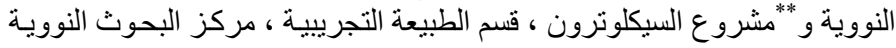

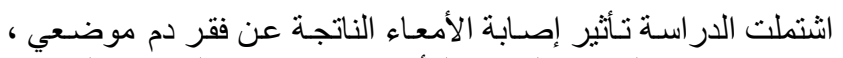

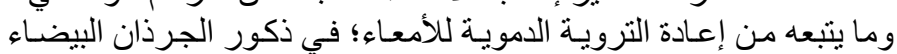

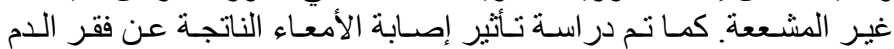

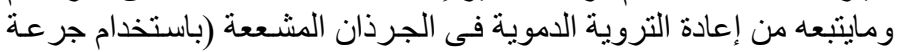

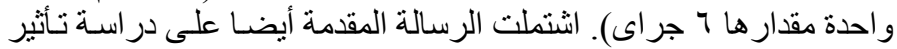

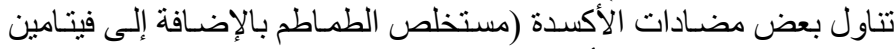

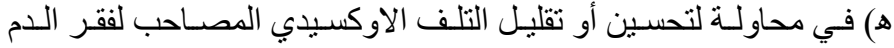

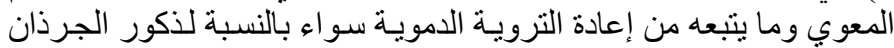

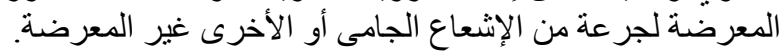

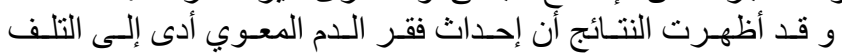

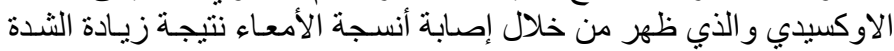

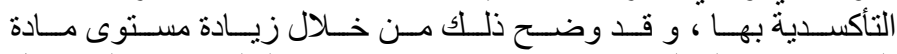

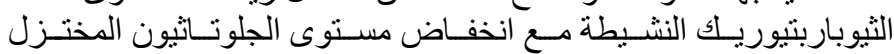

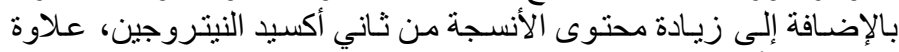

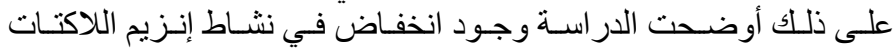

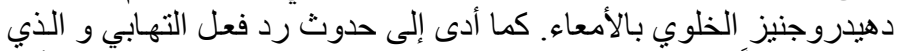

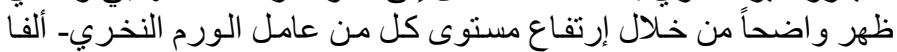

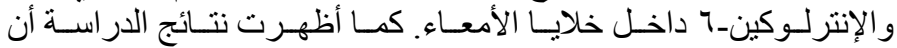

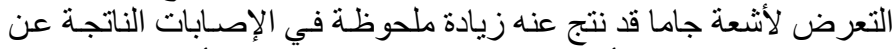

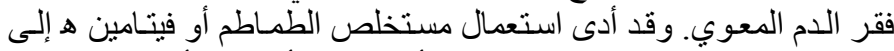

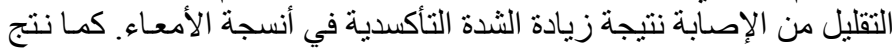

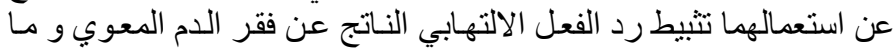

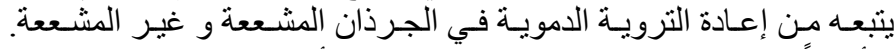

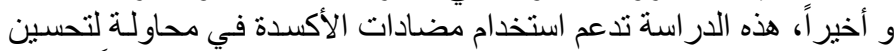

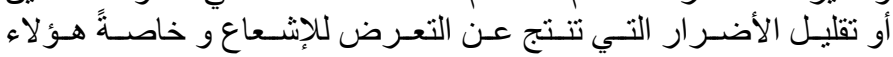

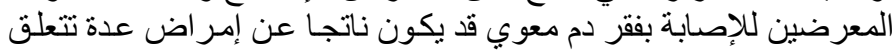
باختلال في الدورة الدموية.

Egypt. J. Rad. Sci. Applic., Vol. 24, No. 2 (2011) 